\title{
REFLEXÕES RELACIONADAS AO TRABALHO DO PROFESSOR NAS ESCOLAS PÚBLICAS E O ABSENTEÍSMO
}

\author{
Aline de Souza ${ }^{1}$, Yoshie Ussami Ferrari Leite ${ }^{2}$ \\ ${ }^{1}$ Mestranda do Programa de Pós-Graduação em Educação da Universidade Estadual Paulista - UNESP, Presidente \\ Prudente, SP. E-mail: aline.niisouza.ppge@gmail.com \\ ${ }^{2}$ Doutora em Educação pela Universidade Estadual de Campinas - UNICAMP. Professora Adjunta do Departamento de \\ Educação e do Programa de Pós-Graduação em Educação da Universidade Estadual Paulista - UNESP, Campus de \\ Presidente Prudente, SP.
}

\section{RESUMO}

O presente artigo tem por objetivo refletir sobre as transformações do trabalho docente e os efeitos no absenteísmo, por meio de um levantamento de teses e dissertações realizado junto aos Programas de PósGraduação em Educação de quatro universidades (USP, PUC-SP, UNICAMP e UERJ). Elegemos o período entre 2006 à 2016 e os descritores utilizados foram "absenteísmo", "precarização", "mal-estar docente", "ausência ou falta de professores". Com a busca foi possível selecionar seis dissertações, sendo que esses estudos foram realizados no âmbito da escola pública e derivam das condições de trabalho do professor, precarização e complexidade de sua função, ocasionando o adoecimento destes profissionais e as justificativas de suas ausências. Concluímos que há a necessidade de garantir ao professor condições dignas de trabalho que superem as dificuldades e favoreçam a valorização e efetivação do profissionalismo docente.

Palavras - chave: Absenteísmo. Trabalho do professor. Precarização Docente. Escolas Públicas.

\section{REFLECTIONS RELATED TO THE TEACHER'S WORK IN PUBLIC SCHOOLS AND ABSENTEEISM}

\section{ABSTRACT}

The purpose of this article is to reflect on the transformations of teaching work and the effects on absenteeism, through a survey of theses and dissertations carried out with the Postgraduate Education Programs of four universities (USP, PUC-SP, UNICAMP and UERJ). We chose the period from 2006 to 2016 and the descriptors used were "absenteeism", "precariousness", "teacher malaise", "absence or lack of teachers". With the search it was possible to select six dissertations, being that these studies were carried out within the public school and derive from the working conditions of the teacher, precariousness and complexity of their function, causing the sickness of these professionals and the justifications of their absences. We conclude that there is a need to guarantee to the teacher decent working conditions that overcome the difficulties and favor the valorization and effectiveness of teaching professionalism.

Keywords: Absenteeism. Teacher's work.Precarious teaching.Public schools.

1. INTRODUÇÃO

\author{
"E toda a humana \\ docência \\ Para inventar-se um \\ ofício \\ ou morre sem exercício \\ ou se perde na \\ experiência..." \\ Cecilia Meireles
}

A proposta deste artigo surgiu a partir de conhecimentos e discussões acerca da profissão docente na disciplina intitulada "Profissão Docente, Caracterização, Perspectivas e Espaços de Formação", vinculada ao Programa de Pós-Graduação em Educação, da Faculdade de Ciências e Tecnologia (UNESP), em Presidente Prudente - SP. Com esse propósito, articulamos as leituras de autores realizadas na disciplina com o levantamento de teses e dissertações sobre o absenteísmo e o trabalho docente realizado em quatro Universidades (PUC-SP, USP, UERJ e UNICAMP). 
Em busca de resgatar a trajetória que constituiu o ofício docente, Arroyo (2000, p. 25) usa a expressão "ofício de mestre" com o intuito de "chamar a atenção para essa longa história, para procurar nossa identidade longe, para nos ver como uma construção social, histórica, cultural que finca raízes fundas no passado".

Sobre a busca da identidade docente, Arroyo (2000) nos ajuda a refletir sobre a lacuna e dificuldade em reconhecer a profissão do professor enquanto luta social "[...] sabemos pouco sobre nossa história. Nem nos cursos normais, de licenciatura e pedagogia nos contaram quanto fomos e quanto não fomos. O que somos". (ARROYO, 2000, p.29). Por causa disso, o professor tem dificuldade em refletir sobre as mudanças no trabalho docente e articular os acontecimentos atuais com a história do passado.

As condições de trabalho docente envolvem questões que evidenciam a profissionalização da categoria como avanço e qualificação do magistério, porém é importante relembrar, utilizando as ideias de Fanfani (2007, p.343), que o ofício docente "siempre tendió a definirse como una mezcla no siempre equilibrada de profesionalismo y de vocación. La idéia de "misión" impone um deber de humildad y dedicación cualidades clásicas del buen maestro de escuela." Ainda o autor explica que hoje o aspecto determinante da luta por profissionalização

$$
\begin{aligned}
& \text { [...] no pasa por la } \\
& \text { cuestión de una más } \\
& \text { prolongada y mejor } \\
& \text { formación de los } \\
& \text { docentes sino por la } \\
& \text { cuestión del control } \\
& \text { sobre el desarrollo del } \\
& \text { oficio. Este esse lado más } \\
& \text { conflictivo de la cuestión } \\
& \text { de la profesionalización y } \\
& \text { es aqui donde se } \\
& \text { enfrentan distintas } \\
& \text { posiciones, intereses y } \\
& \text { actores colectivos. } \\
& \text { (FANFANI, 2007, p. 349). }
\end{aligned}
$$

Com a intenção de explicar alguns aspectos que estão implicados na problemática do trabalho docente, Xavier (2014, p. 845) destaca três pontos:
1) a importância de reconhecer que a escola e o professor são construções históricas e que, portanto, nem sempre foram vistos ou se fizeram perceber da forma como são vistos hoje em dia; 2) a percepção de que a escola e o professor é responsável pela permanente criação de um público, ou seja, pela socialização dos indivíduos, que cada vez mais, dependem da experiência escolar e, portanto, da intervenção do professor para se tornarem pessoas capazes de se inserir e de conviver em sociedade; 3) a constatação de que, nos dias atuais, a escola e o professor estão assumindo uma importância cada vez maior e, ao mesmo tempo, tendem a se tornar alvo de críticas que extrapolam os limites de seu preparo profissional e de suas condições de trabalho, sendo, frequente $\mathrm{e}$ injustamente, responsabilizados pelos sucessos escolares.

Além disso, o trabalho do professor tem passado por condições de precarização que se configuram em falta de materiais pedagógicos, péssimas condições estruturais de trabalho, baixos salários, ineficiência do plano de carreira e diversas inquietações que permeiam a prática docente. Todas essas demandas provocam no professor um sentimento denominado "mal-estar" que, segundo Lopes (2001, p.7), é a existência “[...] de uma crise na docência, com origem em mudanças nos parâmetros do exercício profissional e com impacto nefasto no equilíbrio pessoal dos professores e na qualidade da educação". Para escapar desse sentimento, alguns optam por se ausentar da escola e, "[...] com esses afastamentos 
temporários, a tensão e os conflitos provocados pelas dificuldades e pela insatisfação com o trabalho são adiados; não há solução para os problemas, apenas a fuga deles". (LAPO;BUENO, 2003, p. 81).

$$
\text { O conceito que explica a }
$$
ausência/falta no local de trabalho é denominado de "absenteísmo", e de acordo com Chiavenato (1995 apud PORTO, 2010, p. 6), que discorre através da Teoria Geral de Administração, absenteísmo "refere-se às ausências nos momentos em que os empregados deveriam estar trabalhando normalmente". O autor conclui que as causas do absenteísmo são "complexas e faltam estudos no Brasil adequados acerca da análise das causas, valores reais, identificação de seus tipos, qualidade, grandeza e repercussão na produtividade". (CHIAVENATO 1995 apud PORTO, 2010, p. 6).

Delchiaro (2009) apresenta em sua dissertação o conceito de absenteísmo, como sendo uma "[...] palavra de origem francesa (absenteísme) que significa a pessoa que falta ao trabalho ou ausência por diferentes motivos propositais ou por situações alheias à vontade do trabalhador". (DELCHIARO, 2009, p. 31). Em outra perspectiva, Mallada (2006 apud DELCHIARO, 2009, p. 31-32) caracteriza o absenteísmo trabalhista como "[...] toda ausência de uma pessoa no posto de trabalho, nas horas que correspondem a um dia de trabalho, dentro de jornada legal de trabalho. Quer dizer, a ausência nas férias, ou em feriados não é absenteísmo".

Contudo, podemos compreender o direito do professor em ausentar-se da sala de aula, seja por motivos justificados ou injustificados, de acordo com a necessidade do sujeito. Mallada (2006) justifica o absenteísmo como qualquer ausência ao local de trabalho, sendo assim, o fato de o professor se afastar por motivos justificados e de direito, segundo este autor, pode-se considerar absenteísmo.

Entendemos que a explicação desse conceito apresentado por Chiavenato (1995) é pensado no âmbito da Teoria Geral de Administração e o que estamos propondo está relacionado às ausências do professor nas escolas públicas considerando o seu papel social. Desse modo, não podemos medir os impactos das faltas pela produtividade do trabalho, pois estamos tratando de relações humanas que não se medem pelo produto, mas pelo processo advindo da socialização e troca de conhecimentos.

\section{As transformações do Trabalho Docente na lógica do Capital e o Absenteísmo}

De acordo Oliveira (2004), as reformas políticas no campo da educação são comparáveis em termos de mudanças e organização. Nas palavras da autora, "as reformas educacionais dos anos de 1960, que ampliaram 0 acesso à escolaridade, assentavam-se no argumento da educação como meio mais seguro para a mobilidade social individual ou de grupos". (OLIVEIRA, 2004 , p. 1129). Ainda segundo essa autora, na década de 1990,as reformas educacionais tiveram como principal eixo a educação para a equidade social. Portanto, "[...] tal mudança de paradigma implica transformações substantivas na organização e na gestão da educação pública". (OLIVEIRA, 2004, p. 1129).

É evidente que essa transformação produz consequência no trabalho docente, na estrutura e organização da gestão do sistema público de ensino, pois

trazem medidas que
alteram a configuração
das redes nos seus
aspectos físicos e
organizacionais e que
têm se assentado nos
conceitos
produtividade, eficácia,
excelência e eficiência,
importando, mais uma
vez, das teorias
administrativas as
orientações para o
campo pedagógico.
(OLIVEIRA, 2004, p.
1130).

Neste cenário de precarização e falta de autonomia docente, se faz necessário enfatizar que o professor tem a função de ensinar, sendo que

a função de ensinar é socioprática sem dúvida, mas o saber que requer é intrinsecamente teorizador, compósito e interpretativo [...] Prefiro, assim, em vez de prática docente, falar da ação de ensinar, 
enquanto ação inteligente, função num domínio seguro de um saber.( ROLDÃO, 2007, p.101).

O papel do professor não é dirigido
apenas pelo processo de ensinoaprendizagem dos alunos, existem outras estruturas organizacionais que envolvem a função do trabalho docente, sendo elas a própria comunidade, os pais, a gestão escolar, o município, o Estado, as políticas públicas dentre outras. Portanto, o fracasso do professor advém também de forças externas que dificultam o desenvolvimento do seu senso crítico e reflexivo sobre sua ação, ao invés de contribuir, algumas vezes podam a sua autonomia. Desse modo, os professores acabam por entrar em conflito e aceitam seu insucesso perante algumas situações. Como afirma Barroso (2005, p. 186):

[...] os professores são muitas vezes, simultaneamente, educadores, formadores, familiares, parceiros, técnicos sociais e de saúde, animadores de tempos livres; e as escolas, são o lar, a cantina, a associação, o centro cívico, o clube recreativo, a oficina, etc.

A complexidade da profissão docente e o acúmulo de funções que envolvem o trabalho do professor podem ocasionar o adoecimento e o absenteísmo como fuga da realidade imposta.

\section{Saberes e dimensões: A mudança necessária}

Com base nos saberes plurais de Tardif (2013) e as dimensões pedagógicas de Rios (2001) como compromisso político, de mudança e transformação da realidade presentes no trabalho do professor, pode-se minimizar os aspectos relacionados a precarização e o absenteísmo.

Sobre os saberes de experiência do professor, Tardif (2013) afirma que são plurais, compósitos, heterogêneos, porque envolvem, "no próprio exercício do trabalho, conhecimentos e um saber-fazer bastante diversos, provenientes de fontes variadas e, provavelmente, de natureza diferente" (TARDIF, 2013, p. 18). Para este autor, esses saberes podem ser classificados conforme as suas dimensões, como saberes da formação profissional, das disciplinas, curriculares e experienciais.

Assim compreendemos que articulados aos saberes docentes estão as dimensões pedagógicas exploradas por Rios (2001). Que acredita que as dimensões técnica, política, ética e estética não são apenas conhecimentos de caráter referencial, mas também podemos descobri-las em nossas vivências diárias. Portanto, Rios (2001) explica que a dimensão técnica "[...] reporta, assim, à realização de uma ação, a uma certa forma de fazer algo, a um ofício. No seu ofício, alguém faz alguma coisa - aí se requer ou se demonstra alguma habilidade". (RIOS, 2001, p.94). A dimensão política compreende a vida do sujeito em sociedade e o seu comprometimento social.

Ainda seguindo as ideias da autora, a dimensão ética "[...] tem um caráter reflexivo, não normativo". (RIOS, 2001, p.105). Por isso ela faz relação com a dimensão política, pois "[...] é no espaço político que transita o poder, que se configuram acordos, que se estabelecem hierarquias, que se assumem compromissos. Daí sua articulação com a moral - e a necessidade de sua articulação com a ética". (RIOS, 2001,p.104). Por fim, falar sobre a dimensão estética na prática docente "[...] é trazer luz para a subjetividade do professor, subjetividade construída na vivência concreta do processo de formação e de prática profissional". (RIOS, 2001, p. 98).

Segundo Larrosa (2002), a experiência é considerada uma vivência singular e inacabada, onde o sujeito está em constante mudança por sofrer constantes transformações e adquirir novos aprendizados. Neste sentido, o espaço de formação, no caso a escola, pode favorecer a construção do papel social do professor, e

$\begin{array}{lr}\text { emerge, portanto, a } & \text { de } \\ \text { necessidade } & \text { os } \\ \text { estabelecer uma ruptura } \\ \text { com modos } \\ \text { escolarizados } & \text { que } \\ \text { continuam a ser } \\ \text { dominantes na formação } \\ \text { de professores, } \\ \begin{array}{lr}\text { superando a dupla } \\ \text { exterioridade que os }\end{array}\end{array}$




\section{caracteriza}

(exterioridade

relativamente à pessoa

do professor e à escola, como organização). É no sentido desta superação que aponta a articulação entre as dimensões pessoal, profissional e organizacional [...]. ( CANARIO, 1988, p, 23).

Para que haja valorização e o respeito à opinião do professor na tomada de atitudes, é necessário a garantia e qualidade da formação nas escolas. Sobre isso Imbérnon (2016) relata algumas condições e elementos práticos da formação em escolas:

$$
\begin{aligned}
& \text { a formação centrada na } \\
& \text { instituição educacional } \\
& \text { não é apenas uma } \\
& \text { estratégia de formação } \\
& \text { como conjunto de } \\
& \text { técnicas } \\
& \text { procedimentos, mas tem } \\
& \text { uma carga ideológica, de } \\
& \text { valores, de atitudes, de } \\
& \text { crenças. Não é, portanto, } \\
& \text { uma simples } \\
& \text { transferência física, nem } \\
& \text { tampouco um novo } \\
& \text { agrupamento de } \\
& \text { professores para formá- } \\
& \text { los, mas um novo } \\
& \text { enfoque para redefinir os } \\
& \text { conteúdos, } \\
& \text { as } \\
& \text { estratégias, a instituição, } \\
& \text { os protagonistas e os } \\
& \text { propósitos da formação. } \\
& \text { (IMBERNÓN, 2016, p. } \\
& \text { 156). }
\end{aligned}
$$

Essa condição não é tão fácil de ser assegurada, visto que no interior das escolas também ocorrem situações que inviabilizam essa prática, mas não é impossível de ser concebida por um grupo de professores comprometidos com esse espaço educativo. Como afirma Contreras ( 2002, 100-101), em relação

aqueles professores que entendem que seu trabalho consiste na aplicação de habilidades para alcançar determinadas aprendizagens tendem a resistir à análise de circunstâncias que ultrapassa a forma pela qual já compreenderam seu trabalho. Não aceitarão, como parte de seu compromisso profissional, algo que ultrapasse os limites da ação educativa, já que é na limitação desse contexto que têm mais oportunidades para definir a situação de uma forma rigorosa e concreta.

O sucesso e a valorização da profissão docente estão articulados ao ideal de transformação, o professor que compreende o seu papel social, político e profissional consegue buscar alternativas para que seu trabalho seja fundamentado em atitudes significativas, não se limitando a imposições ideológicas, mas refletindo sobre elas na construção de sua autonomia.

Podemos refletir sobre a figura do bom professor como aquele capaz de transformar a sua realidade sob a luz de seu comprometimento social, esse profissional compreende seu papel de intelectual em um espaço democrático e não se deixará resignar por situações de conflitos, antes refletirá sobre elas.

Em colaboração a esse processo, Giroux (1997) afirma que os formadores de professores precisam levar aos futuros docentes um discurso que desenvolva

[...] uma a linguagem da crítica e a linguagem da possibilidade de forma que os educadores sociais reconheçam que podem promover mudanças. Desta maneira, eles devem manifestar contra as injustiças econômicas, políticas e sociais dentro e fora das escolas [...]. ( GIROUX, 1997, p. 163).

Para que isso ocorra é preciso ir além, como afirma Ghedin (2003, p.149) sobre a prática da epistemologia crítica, pontuando que o horizonte da reflexão no ensino é 
[...] a potencialidade ou deve ser potencializador do questionamento radical de si mesmo e da educação como possibilidade de rompimento da exploração, reproduzido ideologicamente por meio da escola. Tal situação não se dá de forma mecânica, mas é um processo de luta que começa com a reflexão e se traduz em ação concreta, imprimindo nova reflexão e um novo fazer diferenciado [...].

Portanto é fundamental reconhecer que as mudanças da lógica do capital sobre as reformas políticas da educação provocaram uma nova reorganização das escolas e do sistema público de ensino, permitindo a precarização do trabalho docente e, consequentemente, $\mathrm{o}$ absenteísmo de professores como fuga da realidade existente. $O$ presente artigo tem, então, como objetivo refletir sobre as transformações do trabalho docente e os efeitos no absenteísmo, por meio de um levantamento de teses e dissertações realizado em quatro universidades.

\section{DESENVOLVIMENTO}

A princípio, o foco em conhecer a produção dos trabalhos acadêmicos sobre o absenteísmo de professores e deu pelo interesse em realizar uma pesquisa, em nível de mestrado, no Sistema Municipal de Ensino de Presidente Prudente -SP, sobre o absenteísmo e a percepção dos professores em relação ao seu direito, considerando o seu papel social, político e profissional. Visto que a referida pesquisa está em andamento, apreciamos ser este o passo inicial para ampliarmos o nosso universo de compreensão sobre a temática e aprofundarmos nos referenciais teóricos trabalhados pelos autores.

Em busca de conhecer a temática do absenteísmo, especificamente relacionado ao trabalho do professor, foi realizado um levantamento sobre os trabalhos já publicados no âmbito acadêmico, elegendo o período de
2006 a 2016 em quatro universidades: Universidade de São Paulo (USP), Universidade Estadual de Campinas (UNICAMP), Pontifícia Universidade Católica de São Paulo (PUC-SP) e Universidade Estadual do Rio de Janeiro (UERJ).

A escolha das referidas universidades levou em consideração a tradição em produções de trabalhos no campo de formação de professores e outras questões referentes às condições de trabalho docente em algumas universidades públicas, exceto a PUC-SP. Portanto, a escolha dessa última se deu pelo fato de ser uma das universidades pioneiras do Estado de São Paulo.

O levantamento foi realizado em bases de dados dos cursos de Pós-Graduação em Educação das Universidades citadas. O Programa de Pós-Graduação em Educação da USP é reconhecido pela CAPES, sendo avaliado com nota seis em uma escala de três a sete (FEUSP, 2017). A PUC-SP possui seis programas de Pós-Graduação em Educação, especificados por área de conhecimento. Em meio aos achados, quatro pesquisas foram encontradas junto ao Programa de PósGraduação em Educação História, política, sociedade, avaliado pela CAPES no triênio 2010-2012 com conceito quatro (PPGES, 2017). E uma pesquisa selecionada junto ao Programa de Pós-Graduação em Educação Currículo, também avaliado pela CAPES, com nota cinco no triênio 2010-2012. (PPGES, 2017).

$\mathrm{Na}$ Universidade Estadual de Campinas, o levantamento foi realizado junto ao Programa de pós-graduação em Educação, que inclui os Cursos de Mestrado e Doutorado, e tem sido recomendado pela CAPES com nota cinco (PPGFE, 2017). O Programa de Pós-Graduação em Educação (PROPED, 2017) da Universidade Estadual do Rio de Janeiro é avaliado com nota sete pela CAPES.

Para a busca, utilizamos os descritores "absenteísmo", "precarização docente", "malestar docente", "ausência e falta de professores", individualmente e em conjunto. A seleção considerou título, palavras-chave e resumos, e, a partir de uma leitura mais aprofundada, exploramos nos trabalhos os referenciais teóricos e metodológicos percorridos pelos autores. 


\section{RESULTADOS}

Com a finalidade de apresentarmos os resultados desse levantamento de teses e dissertações sobre a temática do absenteísmo relacionado ao trabalho docente, copilamos, a seguir, na tabela 1 , os dados numéricos

Tabela 1. Levantamento de Teses e Dissertações vários aspectos que envolvem também o absenteísmo de professores.

As demais pesquisas selecionadas (05) foram encontradas no banco de teses e dissertações da PUC-SP. A dissertação de Santos (2006) com o título As faltas de professores e a organização de escolas na rede municipal de São Paulo, como também a

Universidades Total Encontrados Selecionadosłissertação de Gesqui (2008), intitulada Organização da escola, absenteísmo docente, discente e rendimento escolar, sendo ambas

\begin{tabular}{lccc}
\hline USP & 1623 & 05 & 01 \\
\hline PUC-SP & 4923 & 10 & 05
\end{tabular}
orientadas pela ProfáDra Alda Junqueira Marin. As duas dissertações discutem o absenteísmo de professores a partir de um aparato legal que possibilita a ausência dos docentes da sala de aula, e os autores

$\begin{array}{lllll}\text { UNICAMP } & 3580 & 05 & 00 & \begin{array}{l}\text { pontuam que compete ao gestor uma } \\ \text { reorganização da escola para lidar com tal } \\ \text { situação. }\end{array} \\ \text { UERJ } & 6251 & 14 & 00 & \end{array}$
UERJ $6251 \quad 14 \quad 00 \quad$ A terceira dissertação selecionada da autora Delchiaro (2009), com o título Gestão

Fonte: As Autoras.

De acordo os dados apresentados na tabela 1, esclarecemos que 0 total de trabalhos é referente a quantidade geral de produções acadêmicas (16.377) eleito pelo período de 2006 a 2016 nos Programas de Pós-Graduação em Educação de cada universidade. De acordo os descritores, separamos os trabalhos encontrados (34) e por fim apenas selecionamos (06) aqueles que estavam relacionados a temática do absenteísmo. Verificamos que mediante o total de trabalhos alocados em cada universidade, apenas $0,2 \%$ foram encontrados de acordo os descritores, e mais especificamente, $0,03 \%$ do total trabalharam com a temática do absenteísmo.

Uma dissertação foi selecionada junto ao Programa de Pós-Graduação Saúde, Ciclos da Vida e Sociedade da USP, com autoria de Porto (2010) e intitulada Faltas e licenças médicas, o absenteísmo na Secretaria de Estado da Educação de São Paulo, sob orientação do Prof. Dr. Paulo Rogério Gallo. Essa pesquisa teve por objetivo medir as taxas de absenteísmo no trabalho ligadas aos motivos de saúde entre educadores e servidores da Secretaria de Estado da Educação de São Paulo. Este trabalho adquire relevância em razão de debruçar-se sobre escolar e absenteísmo docente: diferentes olhares e diversas práticas. Validação de uma experiência na rede municipal de São Paulo, orientada pela ProfaDra Regina Lúcia Giffone Luz de Brito. A autora apurou a redução do absenteísmo docente no período de quatro anos e afirma que o enfrentamento desse fenômeno se deu a partir de um projeto de gestão desenvolvido na escola que valorizou os professores protagonistas e sua formação continuada.

A quarta dissertação teve autoria de Spinelli (2009), intitulada $O$ absenteísmo laboral docente em uma escola Estadual em São José dos Campos e sua relação com bônus mérito, foi orientada pela Profáara Helena Machado de Paula Albuquerque. A pesquisa aponta a relação entre o absenteísmo docente e o bônus mérito, e a autora concluiu que, mesmo premiando os professores, a taxa de absenteísmo na escola não foi reduzida.

Por último, citamos a dissertação de Jacinto (2016), com o título de Absenteísmo docente em duas escolas do distrito Jardim Ângela do município de São Paulo, sob a orientação da ProfaDra Leda Maria de Oliveira Rodrigues. $O$ trabalho objetivou analisar 0 absenteísmo docente na visão dos protagonistas e as justificativas dadas às suas ausências.

Com base nos objetivos propostos para este artigo, podemos concluir que ainda existem poucos estudos sobre a temática do 
absenteísmo no campo da educação, pois em alguns momentos da busca foi possível encontrar diversos estudos realizados na área da saúde.

Com o resultado do levantamento de teses e dissertações sobre a temática do absenteísmo de professores e o trabalho docente, conseguimos contemplar três análises. A primeira é sobre a percepção de que alguns trabalhos tratam o mal-estar docente como um sintoma que pode ocasionar o absenteísmo. A segunda análise faz relação com o absenteísmo de professores e a organização escolar. E, por fim, a ligação do absenteísmo com a aprendizagem do aluno.

A maioria das pesquisas selecionadas está relacionada ao trabalho docente, seja em relação ao bônus mérito Spinelli (2009), valorização docente e formação continuada Delchiaro (2009), além de duas pesquisas Santos (2006) e Gesqui (2008) - com foco na reorganização do trabalho escolar quando o professor se ausenta da sala de aula.

Seguindo as análises apresentadas anteriormente sobre 0 resultado do levantamento, consideramos, para este artigo, os trabalhos que se enquadram no segundo diagnóstico, que diz respeito ao absenteísmo de professores com foco na organização escolar e consequentemente faz reflexão sobre o trabalho docente nas escolas públicas. Desse modo, os trabalhos de Santos (2006) e Gesqui (2008) serão alvo de uma análise mais aprofundada.

A dissertação de Santos (2006) intitulada As faltas dos professores $e$ a organização de escolas na rede Municipal de Ensino de São Paulo, buscou "Obter familiaridade com o fenômeno das faltas, determinação da frequência com que ocorre a relação com a organização das escolas". (SANTOS, 2006, p.13). Por meio de um estudo exploratório, a autora escolheu cinco escolas de regiões periféricas diferentes da cidade de São Paulo. Dos 143 professores que responderam ao questionário, 82 docentes declararam acumular cargo.

Em relação aos motivos das faltas o percentual por motivos de saúde foi maior e o modo de organização das escolas para suprir as ausências dos professores apareceu nos questionários como: utilização de professores adjuntos para suprir os professores eventuais, divisão dos alunos entre as classes de mesma série, utilização de outros espaços sem professor, adiantamento de aula e suspensão dos alunos. No entanto, a organização dessas escolas públicas de São Paulo em relação ao absenteísmo, sofre consequência devido à precarização do trabalho docente, pois apresenta um número alto de alunos por sala e a sobrecarga de trabalho, podendo ocasionar o mal-estar dos professores.

A dissertação de Gesqui (2008) com o título Organização da escola, absenteísmo docente, discente e rendimento escolar objetivou

[...] auxiliar na
compreensão da
realidade escolar em seu
dia-a-dia. Tal objetivo se
desdobraria na busca de
constatar a quanto
tempo estaria reduzido o
encontro entre
profissional titular da
disciplina e aluno dentro
do ambiente escolar,
tendo em vista todas as
ausências legais de
professores e alunos
bem como os possíveis
impactos dessa relação
no rendimento dos
alunos. (GESQUI, 2008,
p.12)

Para a realização dessa pesquisa, a autora buscou os registros da trajetória escolar dos alunos, como também os registros dos professores titulares das disciplinas, o motivo de suas ausências e quem o substituiu. A autora concluiu que "[...] há pouca variação no rendimento do alunado no que tange à relação com o atendimento por professores titulares das disciplinas ou eventuais, o que permitiu levantar várias questões sobre a eficiência do que ocorre dentro da sala de aula". (GESQUI, 2008, p. 143). Essa pesquisa foi realizada em uma escola pública de ensino fundamental II da Rede Estadual Paulista, situada na cidade de Franco da Rocha, faz menção ao absenteísmo, organização da escola através das ausências dos professores e à preocupação sobre os possíveis impactos no rendimento dos alunos. A autora pontua que os documentos analisados foram preenchidos em um período em que a escola estava com 
ausência de funcionários, sugerindo a falta de fidedignidade dos fatos.

Pudemos perceber que o trabalho do professor vai além de ministrar aulas, pois ele ainda preenche fichas, cadernetas e documentos em geral. Notamos ainda que esses profissionais fazem uso do espaço da sala de aula para preenchimento dessa papelada ou que acabam levando esse trabalho para casa devido a sobrecarga de trabalho na escola.

Todos esses estudos foram realizados no âmbito da escola pública e investigam as condições de trabalho do professor, a precarização de seu trabalho e a complexidade de sua função, ocasionando o adoecimento destes profissionais e as justificativas de suas ausências.

\section{ALGUMAS CONSIDERAÇÕES}

Através das exitosas discussões realizadas na disciplina intitulada "Profissão Docente, Caracterização, Perspectivas e Espaços de Formação", oferecida pelo Programa de Pós-Graduação em Educação da Faculdade de Ciências e Tecnologia (UNESP) e as ideias dos autores citados neste estudo, buscamos refletir as transformações no trabalho docente e os efeitos no absenteísmo, por meio de um levantamento de teses e dissertações realizado em quatro universidades (USP, UNICAMP, PUC-SP e UERJ).

Atualmente os gestores das escolas públicas tem se deparado com o índice elevado de falta de professores por motivos diversos, acarretando a situação de reorganização do quadro profissional para que os alunos não sejam defraudados em relação ao seu direito à educação de qualidade. Portanto, é evidente que o absenteísmo de professores pode ocasionar 0 baixo rendimento escolar dos alunos, como mostra a pesquisa de Gesqui (2008).

Em síntese, analisando o percentual de produções acadêmicas selecionadas $(0,03 \%)$ sobre a temática do absenteísmo e analisando o objetivo de cada autor, percebemos que nenhuma pesquisa foca a questão da perspectiva do professor em relação ao seu direito em ausentar-se considerando o seu papel social, político e profissional. Por isso, temos a intenção de amadurecer a nossa reflexão nesse sentido em uma pesquisa posterior.

É fundamental entender as transformações das reformas educacionais no contexto de regulação política que reflete no trabalho docente e na organização das redes públicas de ensino. A precarização docente é oriunda dessas mudanças e ocasionada pela falta de clareza e preparo dos profissionais em lidar com as políticas públicas colocadas. Quando a situação de mal-estar se apodera da vida do professor permitindo que o mesmo não encontre estratégias de superação e transformação da realidade através de ações individuais e coletivas, o fenômeno denominado "absenteísmo" se torna presente, favorecendo a ausência do docente como fuga da realidade.

Atribuir ao professorado a culpa pelo fracasso da escola pública é analisar os fatos sem contextualizá-los com a história que constituiu o ofício docente e as reformas que exercem sobre as relações de trabalho dos profissionais da educação. É necessário garantir ao professor condições dignas de trabalho que superem as dificuldades e favoreçam a valorização e a efetivação do profissionalismo docente.

\section{REFERÊNCIAS}

ARROYO, M.G. Ofício de mestre: imagens e autoimagens. Petrópolis, RJ. 70 edição. Editora Vozes. 2000.

BARROSO, J.Políticas educativas e organização escolar. Lisboa, 2005.

CANÁRIO, R. A escola: O lugar onde os professores aprendem. Revista de Psicologia da Educação. PUC - São Paulo, n.6, p 9-27, 1988.

CONTRERAS, J. A. A autonomia de professores. S. P: Cortez, 2002.

DELCHIARO, E.C. Gestão escolar e absenteísmo docente: diferentes olhares e diversas práticasvalidação de uma experiência na rede municipal de São Paulo.2009. 206f. Dissertação (Mestrado em Educação) - Pontifícia Universidade Católica de São Paulo, 2009.

FANFANI, E.T. Consideraciones sociológicas sobre profesionalización docente. Educação \& 
Sociedade, Campinas, v. 28, n.99, p. 335-353, maio/ago.2007.

GESQUI, L. C. Organização da escola, absenteísmo docente, discente e rendimento escolar. 2008. 160f. Dissertação (Mestrado em Educação) - Pontifícia Universidade Católica de São Paulo, 2008.

GHEDIN, E. Professor reflexivo: da alienação da técnica à autonomia da crítica. In: PIMENTA, $S$. G.; GHEDIN, E. Professor reflexivo no Brasil: gênese e crítica de um conceito. São Paulo: Cortez, 2003. p. 129-150.

GIROUX, H. A. Os professores como intelectuais. Porto Alegre: Artes Médicas, 1997. Cap. 9: Professores como intelectuais transformadores, $p$. 157-164.

IMBERNÓN, F. Qualidade do ensino e formação:uma mudança necessária. São Paulo: Cortez, 2016. Cap.9: A formação a partir de dentro: o que é formação em escolas e não nas escolas?

JACINTO, G.J. Absenteísmo docente em duas escolas do distrito Jardim Ângela do Município de São Paulo. 2016. 135f. Dissertação (Mestrado em Educação) - Pontifícia Universidade Católica de São Paulo, 2016.

LAPO, F.R; BUENO, B.O. Professores, desencanto com a profissão e abandono do magistério. Cadernos de Pesquisa, São Paulo, n. 118, p.6588 , mar./2003.

LARROSA, J. Notas sobre a experiência e o saber da experiência.Revista Brasileira de Educação, Rio de Janeiro, n.19, p.20-28. jan./abr. 2002. Disponível em: <http://www.scielo.br/pdf/rbedu/n19/n19a02.pd f>. Acesso em: 09 fev.2016.

LOPES, A. Mal-estar na docência?:visões, razões e soluções. Porto: ASA, 2001.

OLIVEIRA, D.A. A reestruturação do trabalho docente: precarização e flexibilização. Educação \& Sociedade,Campinas, v. 25 , n. 89 , p. $1127-$ 1144, set./dez. 2004. Disponível em: <http://www.cedes.unicamp.br>. Acesso em: 10 set. 2017.
PORTO, M.P. Faltas e licenças médicas, o absenteísmo na Secretaria de Estado da Educação de São Paulo. 2010.102 f. Dissertação (Mestrado em Saúde Pública) - Universidade de São Paulo, São Paulo, 2010.

RIOS, T. A. Compreender e ensinar:por uma docência de melhor qualidade. São Paulo: Cortez, 2001.

ROLDÃO, M.C. Função docente: natureza e construção do conhecimento profissional. Revista Brasileira de Educação, Rio de Janeiro, v.12, n.34, p. 94-103, jan./abr. 2007. DOI https://doi.org/10.1590/S1413247820070001000 $\underline{08}$

SANTOS, S. L. As faltas dos professores e a organização de escolas na rede municipal de ensino de São Paulo. 2006. 140f. Dissertação (Mestrado em Educação) - Pontifícia Universidade Católica de São Paulo, 2006.

SPINELLI, G.G.F. 0 absenteísmo laboral docente em uma escola estadual de São José dos Campos e sua relação com o bônus mérito. 2009. 91f. Dissertação (Mestrado em Educação) - Pontifícia Universidade Católica de São Paulo, 2009.

TARDIF, M. Saberes docentes e formação profissional. 15. ed. Petrópolis: Vozes, 2013.

UNIVERSIDADE CATÓLICA DE SÃO PAULO. Programas de Pós-Graduação em Educação. Página Oficial. Disponível em:<http://www.pucsp.br/posgraduacao/mestrado-e-doutorado/programas $>$. Acesso em: 20 jul, 2017.

UNIVERSIDADE ESTADUAL DE CAMPINAS. Programa de Pós-Graduação da Faculdade de Educação. Página Oficial. Disponível em:<https://www.fe.unicamp.br/posgraduacao $>$. Acesso em: 20 jul, 2017.

UNIVERSIDADE ESTADUAL DO RIO DE JANEIRO. Programa de Pós-Graduação em Educação. Página Oficial. Disponível em: <http://www.proped.pro.br/>. Acesso em: 20 jul. 2017.

UNIVERSIDADE DE SÃO PAULO. Faculdade de Educação. Página Oficial. Disponível em: 
$<$ http://www3.fe.usp.br/pgrad/>. Acesso em: 20 de jul.2017.

XAVIER, L.N. A construção social e histórica da profissão docente. Uma síntese necessária. Revista Brasileira de Educação, Rio de Janeiro, v.19, n. 59 , p. $827-849$, out./dez. 2014.DOlhttps://doi.org/10.1590/S14132478201 $\underline{4000900002}$

Recebido para publicação em: 03/10/2017

Revisado em: 06/11/2017

Aceito em: 18/01/2018 